\title{
Cost effectiveness indicators of residential complex construction project
}

\author{
Pavel Morozovskiy ${ }^{1, *}$, Denis Muradov ${ }^{1}$, Anastasia Udalova $^{2}$, Natalia Samosudova $^{3}$ and \\ Dmitriy Spitsov ${ }^{4}$ \\ ${ }^{1}$ Peter the Great St. Petersburg Polytechnic University, 195251 St. Petersburg, Russia \\ ${ }^{2}$ National Research University Higher School of Economics, 194100 St. Petersburg, Russia \\ ${ }^{3}$ Moscow State University of Civil Engineering, 26, Yaroslavskoye shosse, Moscow, 129337, Russia \\ ${ }^{4}$ Moscow Institute of Architecture, Rozhdestvenka street 11, 107031, Moscow, Russia
}

\begin{abstract}
The article presents the variant of optimization of the project of construction of a residential complex. The study includes the decomposition of the complex into specialized types of work, the preparation of matrices of the works' volumes, the calculation of the duration of construction, the calculation of methods of organization of work in different order, the calculations of the estimated cost of objects. A qualitative risk analysis of the project was carried out.
\end{abstract}

\section{Introduction}

Nowadays, an urgent problem for expanding megacities, in particular St. Petersburg, is the issue of rational and economically attractive reconstruction and development of abandoned industrial zones located in the historical center. For many years, the Northern Capital was built unevenly, industrial districts were built surrounded by residential areas, monuments of culture and architecture, but today most enterprises are no longer functioning, are in disrepair, and often can not be restored [1,2].

\section{MS Project schedule diagram. PERT method assessment of project duration}

The research was conducted in the following sequence.

A decomposition of the complex into specialized types of work was performed:

- Preparatory work;

- Foundation work;

- Frame works;

- HVAC;

- Finishing works;

- Others.

Table 1 includes estimated data on the estimated cost of construction

*Corresponding author: morozovoff85@gmail.com 
Table 1. Complex flow of residential complex.

\begin{tabular}{|c|c|c|c|}
\hline Name & Area, sq. m. & Levels quantity & $\begin{array}{c}\text { Cost, thousand of } \\
\text { rub. }\end{array}$ \\
\hline G corp & 6948.00 & 14 & 217983276.00 \\
\hline H corp & 6678.00 & 12 & 226796616.00 \\
\hline K corp & 4770.00 & 10 & 163897200.00 \\
\hline Parking 3 & 1528.00 & 1 & 54964834.00 \\
\hline Parking 2 & 3268.00 & 1 & 117555679.00 \\
\hline Parking 1 & 3388.00 & 1 & 121872289.00 \\
\hline Sum & 28580.00 & & 903069894.00 \\
\hline
\end{tabular}

The calculation of the duration of capital construction on the basis of the cost in accordance with [3] (Figure 1).

\begin{tabular}{|l|l|}
\hline $\mathrm{c}$ & $\mathrm{r}$ \\
\hline 0.1 & 6.0 \\
\hline 0.3 & 7.0 \\
\hline 0.5 & 8.0 \\
\hline 0.7 & 9.0 \\
\hline 1.0 & 10.0 \\
\hline 1.4 & 11.0 \\
\hline 2.0 & 12.0 \\
\hline 2.6 & 13.0 \\
\hline 3.5 & 14.0 \\
\hline 4.0 & 14.5 \\
\hline
\end{tabular}

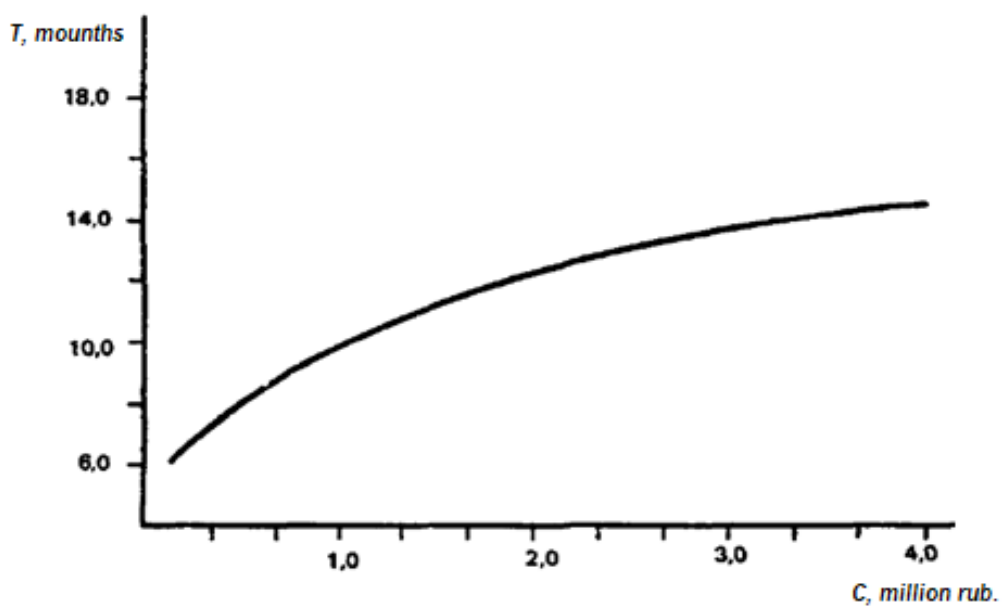

Fig. 1. Duration of construction of residential buildings made of reinforced concrete.

$$
T=A_{1} * C^{A_{2}}, A_{1}=9.96, A_{2}=0.27
$$

Using formula 1 we obtain the durations of each buildings $(\mathrm{k}=232.59$ - correction factor of 08.2018 on indices of changes in the estimated cost of construction in Federal districts and regions of the Russian Federation for August 2018, CAV=1.18). MS Project uses critical path analysis to calculate duration of constraction (Figure 2) [7].

Determination of the optimal method of work organization by the criterion of duration minimization [13].

At capital construction of four large objects the total duration of construction is defined by CMP(construction management plan) $[3,5,10-12]$ taking into account norms for these objects, effective organizational and technological sequence of construction and the most possible combination of construction.

The results of the calculations showed that the minimum duration was obtained in the calculation by the critical path method (hereinafter CPM). The total duration of capital construction of the project was 1269 days [13]. 


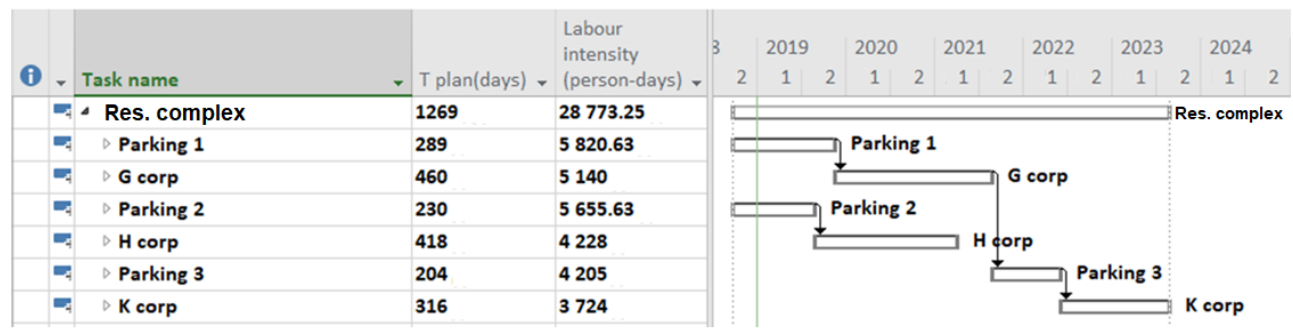

Fig. 2. Works volumes matrix.

After construction, all objects begin to bring the money received by selling real estate and renting parking spaces. There are also maintenance costs, which are included.

\section{PERT method assessment of project duration}

Based on the data obtained, we determine the value of the standard deviation of the normal distribution curve. Using MS Project, fix the boundaries of the project implementation and obtain dispersion (Figure 3).

\begin{tabular}{|c|c|c|c|c|c|c|c|}
\hline & (i) & $\checkmark$ & Task name & $\checkmark$ & T plan(days) & T await(days) & Dispersion \\
\hline 0 & & 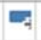 & $\Delta$ Residential complex & & 1269 & 1349.17 & 47.47 \\
\hline 1 & & 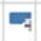 & Parking 1 & & 289 & 289.5 & 12.14 \\
\hline 28 & & $\varpi$ & G corp & & 460 & 516.33 & 21.22 \\
\hline 349 & & 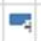 & Parking 2 & & 230 & 0 & 0 \\
\hline 376 & & $\sigma_{4}$ & $D$ corp & & 418 & 0 & 0 \\
\hline 653 & & $\sigma$ & Parking 3 & & 204 & 204.5 & 6.36 \\
\hline 680 & & $\square$ & $\mathrm{K}$ corp & & 316 & 338.83 & 7.75 \\
\hline
\end{tabular}

Fig. 3. Dispersion values.

Sigma value gets:

$$
G=\sqrt{D}=\sqrt{47.47}=6.89
$$

Determining the probability of project completion by a certain point in time.

$$
\begin{gathered}
Z=\frac{T_{\text {plan }}-T_{\text {await }}}{G}=\frac{1269-1349.17}{6.89}=-11.63 \\
P(1342.28(1349.17-6.89)<T<1356.06(1349.17+6.89)=68 \% \\
P(1328.5(1349.17-3 * 6.89)<T<1369.84(1349.17+3 * 6.89)=98 \%
\end{gathered}
$$

The project will not be completed within the specified period (1269 days) with $100 \%$ probability.

\section{Cost effectiveness indicators (NPV, PI, IRR, PBP)}

Each innovative project should be analyzed and evaluated for effectiveness. 
First, a cash flow analysis is carried out, the main purpose of which is to assess the ability of the organization to generate cash in the amount and in the time required for the implementation of the planned expenses. The statement of cash flows is given in figure 4 .

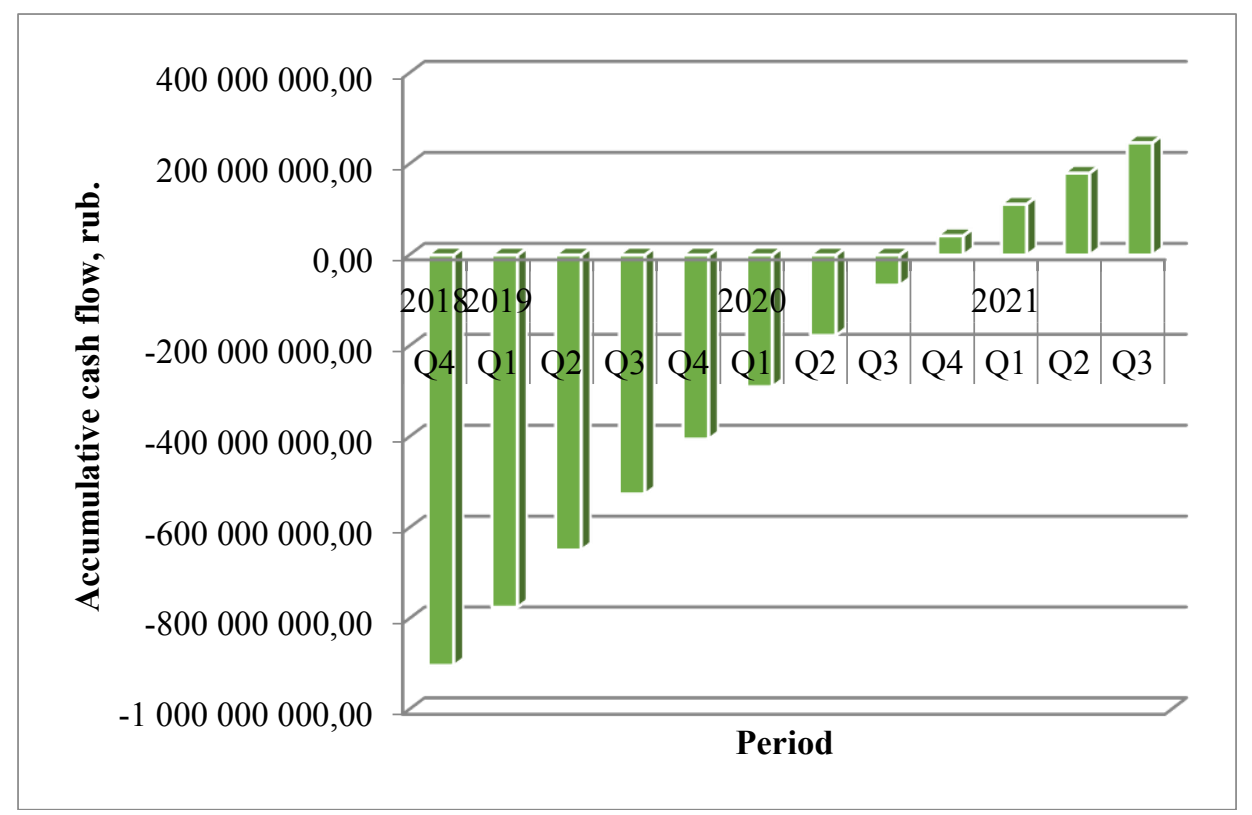

Fig. 4. Accumulative cash flow.

Analysis of the statement of cash flows showed that the cost period begins in the 4th quarter of 2018 and ends in the 3rd quarter of 2020, the total cost is 903069894 rubles.

To analyze the effectiveness of the project, you need to assign a discount rate - this is the interest rate used to convert future revenue streams into a single current value. It consists of a risk-free rate taken equal to the rate of the Central Bank of the Russian Federation $(6.77 \%)$ and the part due to the risk.

Among the risks that affect the purpose of the discount rate, we can distinguish: - the risk of default; - the financial standing of the company; - industry (risks inherent in the construction industry); -the degree of ownership of the company's inflation and exchange rates - country risk.

Taking into account the above factors, in this project the discount rate is equal to $\mathrm{E}=8.25 \%$.

\section{Results and Discussion}

Net present value (NPV) is 108432231.57 rubles.

Profitability index $(\mathrm{PI})=1.273$ - investments are profitable and acceptable in accordance with the chosen discount rate, 1 RUB of invested funds accounts 1.273 RUB of profit.

Internal rate of return (IRR) (quarterly) $=12 \%$, which is more than the discount rate of $8.25 \%$. Therefore, the project will not incur losses, is effective.

Payback period (PBP) is 2 years. 


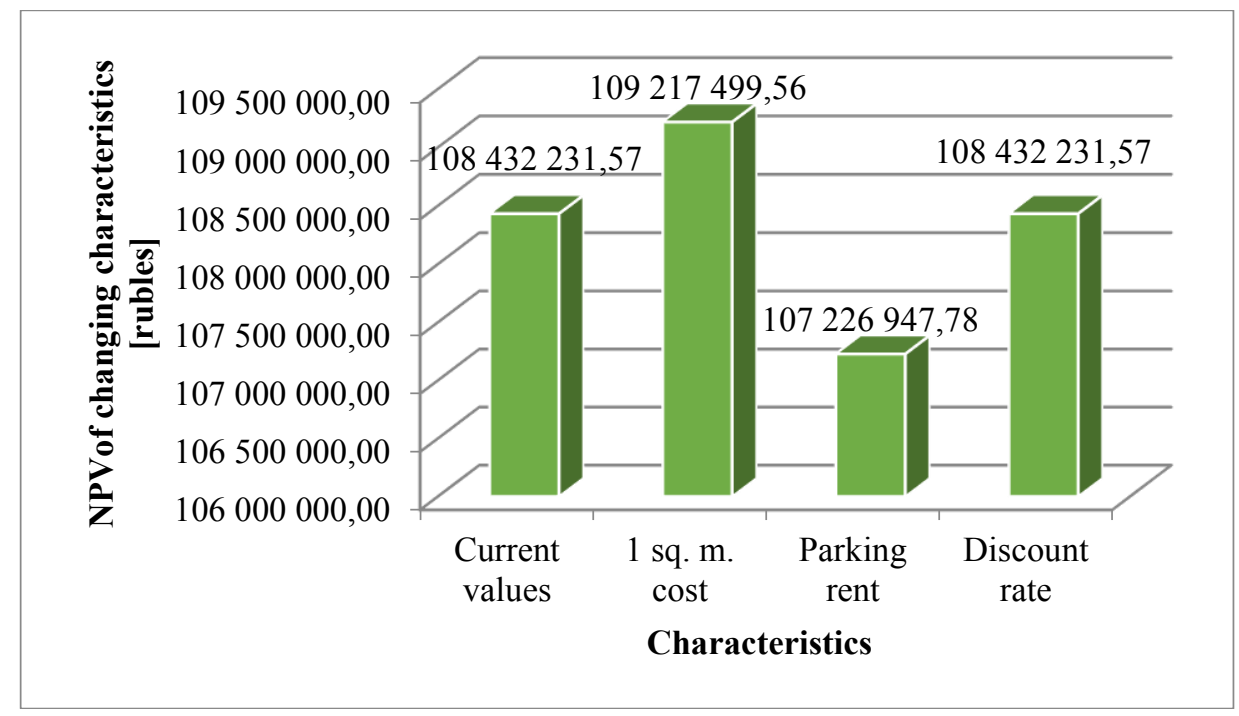

Fig. 5. NPV depending on parameter changes.

\section{Conclusions}

Analysis of the effectiveness of the construction of the residential complex showed that the developed project is effective and investment-attractive. However, it was concluded that the estimated norms and prices are imperfect in the case of a planned reconstruction of industrial areas with the further construction of the residential complex, they distort the real value of the project. These objects must be calculated with the use of specially-designed individual estimate norms taking into consideration all the characteristics and the degree of difficulty and uniqueness of this project.

\section{References}

1. M. Romanovich, A, Vilinskaya, MATEC Web of Conferences, 90, 63-71 (2016)

2. N.V. Braila, Y.G. Lazarev, M. Romanovich, T.L. Simankina, A.V Ulybin, Contemporary problems in building science, engineering and technology (SPbPU, $\mathrm{SPb}, 2017)$

3. Calculated indicators to determine the duration of construction (Stroynormirovaniye, TSITP of the APT, Moscow, 1991)

4. Russian Federation Standard SNiP IV-2-84

5. Russian Federation Standard SNiP 1.04.03-85*

6. V.D. Ardzinov, Pricing and budgeting in construction (Piter, SPb, 2006)

7. I.G. Osipenkova, T.L. Simankina, R.R. Nurgalina, Basics of organization and management in construction, textbook (SPbGASU SPb, 2014)

8. T. L. Simankina, PhD Thesis (Saint-Petersburg, 2007)

9. T. Simankina, O. Sergeenkova, AMM 725-726, 35-48 (2015)

10. I.S. Ptukhina, Simulation of calendar planning in building information modeling programs and regression specification of construction duration norms (SBpPU, St. Petersburg, 2011) 